\title{
Acute opioid poisoning
}

INSERM

\section{Source}

INSERM. (1999). Orphanet: an online rare disease and orphan drug data base. Acute opioid poisoning. ORPHA:35889

Acute opioid poisoning is a rare intoxication with opioids, a large group of alkaloid analgesics, mainly characterized by miosis (pinpoint pupil), respiratory depression (bradypnea/apnea) and central nervous system depression (sedation or coma). Other manifestations include hypotension, reduced bowel motility, hypothermia and hypoglycemia. Naloxone, a competitive inhibitor of the mu-opioid receptor, is a potent antagonist and is used as the antidote for opioid intoxication. 